\title{
Industry-led committee urges delay in closing loophole allowing import of unapproved antibiotics for animals
}

Published at www.cmaj.ca on Apr. 8, 2009.

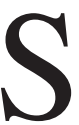

even years after Canadian experts called for tighter rules governing unrestricted imports of unapproved and untested antibiotics used in meat production due to worries that their use contributes to antibiotic resistance in humans, a task force composed primarily of industry representatives is advising Health Canada to bide its time and conduct further studies rather than immediately close a loophole that allows farmers to import such drugs without regulatory scrutiny.

The loophole now allows Canadian farmers to import an estimated \$100million worth of drugs - including drugs not approved for use in Canada - from around the world. Food industry representatives on the task force want Ottawa to keep it open for at least 2 more years while a study is conducted on whether some limited restrictions might work.

In the meantime, Canadian Animal Health Institute data indicate that an estimated one-third of all veterinary drugs used in Canada will continue to be imported with almost no scrutiny from safety regulators. Most antibiotics used by meat producers are given to healthy animals either to accelerate growth or as a prophylactic. Meat producers say the practice is necessary to keep them competitive with producers in the United States and other countries. But public health experts worry that antibiotic-resistant bacteria on meat are contributing to drug resistance in humans.

The government's Task Force on Own Use Importation of Veterinary Drugs' final report was tabled in August 2008, and quietly published by Health Canada on Dec. 30, 2008 (www .hc-sc.gc.ca/dhp-mps/consultation/vet /consultations/oui-iup/consultation-eng .php). Public consultation on its recommendations closed March 5.

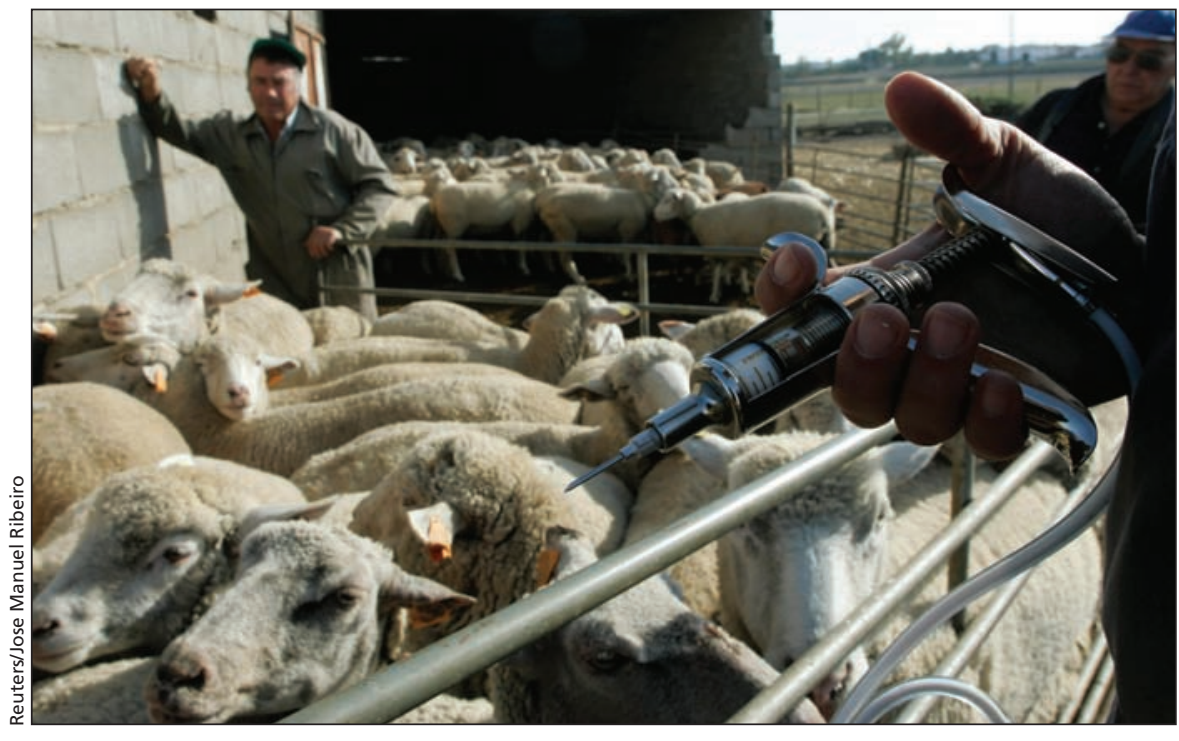

Many Canadian farmers now use a loophole in Health Canada policy in order to import unapproved antibiotics that promote growth of farm animals or that can be used as a prophylactic against illnesses.

"Own use" has been a public health concern since 2002, when a Health Canada advisory committee on animal uses of antimicrobials and their impact on resistance and human health issued a 188-page report listing 38 recommendations, including a request that Ottawa close the loophole by stopping "the importation, sale, and use of antimicrobials not evaluated and registered by Health Canada" (www.hcsc.gc.ca/dhp-mps/pubs/vet/amr-ram_final _report-rapport_06-27_tc-tm-eng.php).

The notion of "own use" stems from the Health Products and Food Branch Inspectorate's Policy on Importations of Drugs for Human Use Including Natural Health Products into Canada, which allows individuals to import a 90-day supply of certain drugs (unless prohibited by law) "for their own use." The regulations allow for the importation of the substances for an "animal for whose benefit it is prescribed."

The own use task force's recommendation to delay regulation of such own use importation galls both public health experts and even some of its own members. "The concern about own use imports in agriculture is: Does the agent in question, the antimicrobial that's being imported, is it going to confer resistance against agents used in humans?" asks Dr. Donald Low, microbiologist in chief at Mount Sinai Hospital in Toronto, Ontario, and coauthor of the 2002 report that called for tighter regulation.

The task force's call for further study is a timid response, Low complains. Its report demonstrates "no concern for the issue of human resistance to antibiotics," he adds. "It's not mentioned in the document. It's not an agenda item."

Instead, says Low, the task force repeatedly refers "to the fact that the licensing of food and drugs in Canada is slow and therefore we need a mechanism to bypass that. It's sort of like, you've got a flat tire and instead of changing the tire, you flatten the others."

Task force member Jenny Hillard, research director for Consumers Alliance Inc., a not-for-profit group based 
in Winnipeg, Manitoba, is also dissatisfied. "I want the loophole closed," she says, adding that unless the current regulatory framework is dramatically changed, primary scrutiny of own use drug imports will continue to come from border agents. "What it comes down to is how closely do they look at your car at the border?"

"What we have is a recommendation that the loophole perhaps be formalized with a bit more paperwork involved," she says. "But there's no suggestion the loophole is being closed," adds Hillard, who notes that the task force - which was not provided with data to quantify the volumes and types of drugs imported under the own use loophole — has essentially come up with a plan that will likely allow farmers to continue freely importing many unregulated drugs.

Fellow task force member Jean Szkotnicki, president of the Canadian Animal Health Institute, says that rather than studying the matter further, regulations should be introduced immediately to force registration of all drugs imported for use in food production. "Canadians would be surprised and up in arms to learn that a significant amount of drugs used in food animal production today are not licensed by Health Canada," she says.

The task force's final report indicates that consensus was not reached on several issues. The group noted, for example, that a restricted import permit program might exclude some drugs from eligibility. But it could not reach consensus on which drugs to exclude.

Nor did the task force agree on whether a study of import restrictions should be conducted before regulations might be devised. Instead, it recommended that another committee be struck by October 2008 to study the issue. The government has not yet done so, says Health Canada Team Leader (Policy and Programs) Lateef Adewoye, who coordinated efforts within the department's Veterinary Drugs Directorate.

Szkotnicki blamed the lack of consensus largely on opposition from the Canadian Cattlemen's Association, which represents Canada's powerful beef industry.

Saskatchewan veterinarian Louis
Desautels, who represented the Canadian Cattlemen's Association on the task force, says regulation on own use is unwarranted until the same drugs are available in Canada at competitive prices. There are no data on volumes of antibiotics entering the country through this loophole, he argues, and thus no evidence confirming a problem.

Closing the loophole would drive up drug prices, adds Desautels, citing the price differential between similar drugs in the US and in Canada. "If you have no competitors for these products, the prices will go up."

Low is most concerned about the impact on antibiotic resistance, particularly front-line infection fighters like third, fourth and fifth generation cephalosporins - a class of antibiotics that the government has deemed crucial to public health. A list compiled in 2000 of 379 so-called "new drugs" for which safety and effectiveness have not been determined by Health Canada but which may currently be available for animal use can be found at www.hcsc.gc.ca/dhp-mps/vet/legislation/guideld/vet_drug-drogues_list-eng.php.

Low notes that the use of fluoroquinolone antibiotics in agriculture in
Spain was strongly suspected of causing urinary tract infections resistant to fluoroquinolone antibiotics in adults and children, (Antimicrob Agents Chemother 1999;43[11]:2736-41). "That's probably the closest we can come to showing the consequence of the use of these agents in agriculture."

The 2002 advisory committee on which Low sat also urged the government to evaluate and register all antimicrobials used in food animals, whether manufactured domestically or imported, including those imported in bulk, which "should be allowed into Canada only under permit."

Large quantities of antimicrobial chemicals are currently being imported into Canada as raw chemicals by animal feed producers and factory farm operators, says Ron Clarke, a veterinarian with the Alberta Department of Agriculture who served on both the task force and the 2002 advisory committee. This practice allows meat producers to bring in large volumes of antibiotics that are considered to be of critical importance in human medicine, such as third generation cephalosporins, without scrutiny.

Questions also exist about the strin-

\section{Box 1: Task Force on Own Use Importation of Veterinary Drugs}

The membership and affiliations of the government's Task Force on Own Use Importation of Veterinary Drugs were, as follows:

- Louis Desautels (and alternate Rob McNabb) - Canadian Cattlemen's Association

- Clare Schlegel (and alternate Morgan Radford) - Canadian Pork Council

- Jean Szkotnicki - Canadian Animal Health Institute

- Rejean Bouchard - Dairy Farmers of Canada

- Jenny Hillard - Consumer Interest Alliance, Inc.

- Gordon Dittberner - Canadian Veterinary Medical Association

- Conrad L'Ecuyer - Canadian Veterinary Medical Association

- Christianne Gagnon - representing provincial veterinary bodies (former president of the Ordre des médecins vétérinaires du Québec

- Ron Clarke - representing provincial governments (veterinarian, Alberta Department of Agriculture)

Ex-officio and/or secretariat:

- Siddika Mithani (and lawyers) - Veterinary Drugs Directorate

- Steve Lavergne - Agriculture and Agri-Food Canada and Foreign Affairs and International Trade

- James Bellis (and alternate Jenny McLaughlin) - Health Canada Inspectorate

- Glen Gifford - Veterinary Biologics Section, Canadian Food Inspection Agency

Source: Health Canada. 
gency of drug production quality standards, Clarke adds. "We've got large volumes of antimicrobial compounds coming in from Shanghai and New Delhi or wherever else - these are places where there is nothing like the control of production quality that Health Canada requires of Canadian antibiotic distributors."

Clarke believes these drugs are being used without veterinary supervision in some factory farms. "This is a practice everybody but those importing the drugs would like to see stopped."

But Health Canada's Adewoye says it's not clear whether the issue of raw chemical imports could be dealt with in the same fashion as own use imports. "We do not have a separate study to look at that."

Others say that the task force's composition (Box 1), and the process by which it operated, were entirely inadequate. No public health experts served on the task force, which included officials from the pork, dairy, beef and pharmaceutical industry associations.

Low and Hillard question how public health experts were left off. "I don't see anybody with the expertise that I'm aware of either federally or provincially in antimicrobial resistance in agriculture or in human health," says Low.

But Adewoye defends the decision not to include public health experts, even though the task force was organized in response to concern for human safety arising from antibiotic use in meat production. "The issue is not about whether we have representatives from all the major stakeholders," he says.

Public health representatives were welcome to provide input during the 9week consultation period, adds Adewoye, a microbiologist who has published warnings in the scientific literature about antimicrobial resistance arising from veterinary use of drugs such as cephalosporins, a key class of drugs in clinical use that are used in unquantified volumes in Canadian meat production.

The 9-week consultation period, however, was limited by technical difficulties. Although Health Canada's Veterinary Drugs Directorate released information about the consultations, with a link to the task force's report, on its website, the link was dysfunctional

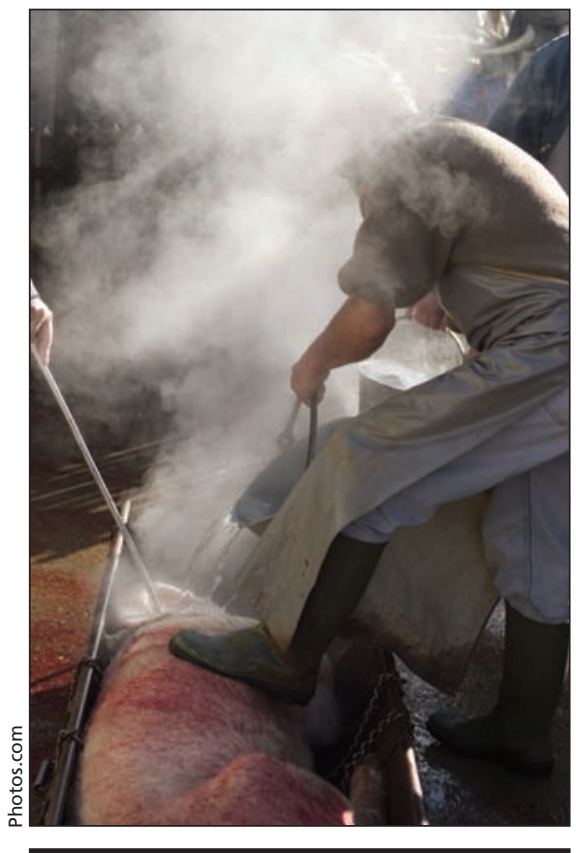

Public health experts have expressed concern that antibiotic-resistant bacteria on meat have enormous ramifications for human health, particularly in that they may confer resistance against agents used in humans.

for a period of 5 weeks and only became operational after $C M A J$ made inquiries. Peter deRosenroll, the directorate's manager of strategic planning and management services, ascribed this problem to a broken weblink. The consultation period was not extended.

It's not the first time that the government's handling of the process has been questioned. In 2007, the Beyond Factory Farming coalition, a Saskatchewan group that opposes nontherapeutic drug use, petitioned the Auditor General of Canada to investigate whether the government was deliberately "dragging its feet."

Petition author Cathy Holtslander says the own use controversy "illustrates the conflict between public safety and commerce," and reveals the extent to which "the government is willing to sacrifice public safety in order to help [Canada's] big meat industry remain competitive in selling to the States."

"The lack of consensus reflects the vested interests of the bodies consulted - the pharmaceutical industry wants only their brand-name patented products allowed, the hog industry and the cattle industry want the cheapest (generic) source of drugs to be allowed," she explains. "There was no public interest group looking out for the health of Canadian consumers of meat, dairy and eggs. This 'consultation' process looks more like an attempt to manufacture consensus."

Even government health investigators have previously warned that there's a looming public health crisis because of the link between the use of antibiotics in animals and human resistance to these antibiotics.

Michael Mulvey, chief, Antimicrobial Resistance and Nosocomial Infections, National Microbiology Laboratory for the Public Health Agency of Canada, has warned that resistance is growing to key front-line drugs such as cephalosporins and that "many arguments" suggest that animals or food are a source of bacteria that transfer resistance to such key drugs to humans (Microbes Infect 2006;8:1945-54).

In a study of antimicrobial usage on Ontario cattle farms, another agency scientist, Carolee Carson, noted that tracking the actual usage of drugs including cephalosporins is extremely difficult but that farmers frequently administer some drugs used in human medicine at dosage levels higher than recommended by Health Canada (Can $J$ Vet Res 2008;72[2]:109-18).

"There is a big gap in what we know about the use of drugs on farms," Carson says.

Similarly, a Health Canada team including Adewoye warned that resistance to cephalosoporins is a serious public health problem, (Vet Microbiol 2007;121[3-4]:197-214).

But lead author and Head of Health Canada's Veterinary Drug Directorate Human Safety Division Xian-Zhi Li now downplays the risks. "Our review was prepared 3 years ago," he said in an email. "I don't think I have followed up new literature enough."

Adewoye says the government is now mulling the task force's recommendation that nothing be done about own use imports until further studies are completed. "We will act when we are ready," he says. - Aruna Handa and Paul Webster, Toronto, Ont.

DOI:10.1503/cmaj.090525 